\title{
Propranolol and Somatostatin Agonist Therapy Resulting in Symptom Improvement and Stabilization of von Hippel-Lindau-Associated Hemangioblastoma: A Case Report
}

Maran Ilanchezhian

National Cancer Institute

Reinier Alvarez

NINDS: National Institute of Neurological Disorders and Stroke

Amanda Carbonell

National Cancer Institute

Brigitte C. Widemann

National Cancer Institute

Prashant Chittiboina

NINDS: National Institute of Neurological Disorders and Stroke Jaydira Del Rivero ( $\square$ jaydira.delrivero@nih.gov )

National Cancer Institute https://orcid.org/0000-0001-9710-4030

\section{Research Article}

Keywords: hemangioblastoma, VHL, somatostatin agonist, propranolol, case report

Posted Date: March 19th, 2021

DOI: https://doi.org/10.21203/rs.3.rs-330233/v1

License: (c) (i) This work is licensed under a Creative Commons Attribution 4.0 International License.

Read Full License 


\section{Abstract}

Von Hippel-Lindau disease is an inherited, autosomal dominant tumor predisposition syndrome which leads to susceptibility for developing hemangioblastomas of the central nervous system and retina, as well as other tumor types. No approved systemic therapies exist for this disease. Here, we present a patient diagnosed with Von Hippel-Lindau disease, with central nervous system and retinal hemangioblastomas, treated with propranolol and subsequently with Lanreotide. On both treatments, the patient showed notable symptom improvement. In addition, since starting Lanreotide, the patients hemangioblastoma has remained stable on imaging. Based on the symptom improvement in this patient and other reported findings in the literature, propranolol and somatostatin agonist therapy may have an anti-tumor effect in Von Hippel-Lindau associated hemangioblastomas; however, further investigation is warranted.

\section{Introduction}

Von Hippel-Lindau (VHL) disease in an inherited, autosomal dominant tumor predisposition syndrome caused by germline mutations in the VHL tumor suppressor gene $[1,2]$. This germline mutation is found in approximately 1 in 36,000 individuals [3]. Affected individuals are susceptible to developing hemangioblastomas (HBs) of the central nervous system (CNS) and retina, renal cell carcinomas (RCCs), endolymphatic sac tumors, pheochromocytomas and pancreatic neuroendocrine tumors $[2,4]$. Patients with VHL disease can be divided into types 1 and 2, based on the probability of developing pheochromocytoma, with type 2 disease carrying the higher risk of pheochromocytoma $[2,5]$.

Due to the development of a variety of different benign and malignant neoplasms, patients have a median survival ranging between 40 and 52 years, the shortest amongst cancer predisposition syndromes [6]. The leading causes of morbidity and mortality in these patients are RCC and CNS HB [7, 8]. The treatment for VHL associated RCC and CNS HB is surgery [7]. However, if surgery is not a viable option, there are no approved systemic therapies that have gained widespread use for the treatment of VHL related CNS HB [2, 7]. The natural history of VHL-associated CNS HB was described in a recent longterm study of 225 patients with VHL. On that study, $51 \%$ of all CNS HB were stable in size during longterm follow-up and $49 \%$ of all CNS HB grew. The most common pattern of growth was saltatory $(72 \%$ of growing tumors), followed by exponential (22\%) and linear (6\%). This led to the understanding that growth rate is necessary to assess the efficacy of surgical vs. nonsurgical therapies [8].

In addition, retinal HBs are typically the most common and earliest presentation of VHL disease $[9,10]$. They occur in about $50 \%$ of VHL patients and are the first tumor to arise in 1 out of 3 cases. Peripheral retinal HBs can be treated with photocoagulation for small tumors and cryotherapy for larger tumors [11]. However, these treatments cannot be used if the tumor is near the optic nerve. In such cases, the common therapeutic approach is surveillance, due to the high risk of damaging the optic nerve [2]. Currently, surgical resection of growing, symptomatic HBs is the only treatment option for these tumors. Despite the 
improvement in the understanding of the pathophysiology of hemangioblastomas, no effective treatment strategy has demonstrated clinical efficacy in retinal HBs in addition to VHL associated CNS HB.

Propranolol hydrochloride an FDA approved agent, is a synthetic B1 and B2 adrenergic antagonist that has been marketed for over 50 years, and whose safety has been well reported [12]. It is used for the treatment of hypertension, cardiac arrhythmias, and is effective in treating infantile hemangiomas $(\mathrm{IH})$ $[13,14]$. Moreover, IH VHL associated HBs have similar histologic appearance and pathogenesis. Albinana et. al, showed that propranolol may have efficacy in the treatment of retinal HBs, in a study where 7 patients with retinal HBs showed stable disease over a period of 12 months [15]. In addition, a study by Shepard et. al, showed propranolol activity in in-vitro models of VHL RCC and CNS HB, in addition to retrospective data suggesting that propranolol may slow HB growth in VHL patients [16].

${ }^{68} \mathrm{Ga}$-DOTATATE positron emission tomography (PET) imaging of VHL patients has shown that VHL-HBs have avidity to somatostatin analogues [17-19]. Neuroendocrine tumors that express somatostatin receptors (SSTRs) demonstrate a clinical response to somatostatin analogue therapy $[20,21]$ and this has been demonstrated in VHL related pancreatic neuroendocrine tumors as well [22]. Sizdahkhani et. al, showed that the somatostatin receptor agonist octreotide showed efficacy both in-vitro and in off label use in a patient with advanced VHL HB [23], suggesting that it may have potential as a therapy for VHL associated HB. Here we present a case of a patient with VHL-associated CNS HBs and retinal HBs, treated with propranolol and subsequently with Lanreotide. On both treatments, the patient showed notable symptom improvement with pain reduction and optimal sleep quality. In addition, since starting Lanreotide, the patient's hemangioblastoma remained stable on imaging.

\section{Case Presentation}

A 16-year-old Caucasian male initially presented with impaired vision due to a retinal hemangioblastoma. This was unsuccessfully treated with laser treatment, followed by cryoablation and eventually resulting in the loss of vision in his left eye. Genetic testing revealed a heterozygous cysteine (C) to guanine (G) base change at nucleotide 469 of his VHL gene, resulting in a codon change at position 86 (proline CCC to one for alanine GCC). The mutation was consistent with type $1 \mathrm{VHL}$.

At the age of 23 years, a left adrenal nodule, measuring about $1.4 \mathrm{~cm}$ was noted on computerized tomography (CT) imaging. The patient subsequently enrolled on the VHL natural history study at the National Institutes of Health at this time (NCT00005902). The adrenal nodule has been monitored with plasma and/or urine catecholamine and metanephrines measurement, and meta-iodobenzylguanidine (MIBG) imaging, both of which have been normal. The patient has not had any history of hypertension during this period. At the age of 28 years, a $1.7 \mathrm{~cm}$ right kidney solid lesion was noted on CT imaging, which was suggestive of RCC. Over the next 3 years, this right renal lesion grew up to $3 \mathrm{~cm}$. $\mathrm{He}$ subsequently enrolled on a clinical trial with sunitinib (NCT00330564- "Evaluation of Sunitinib Malate in Patients With von Hippel-Lindau Syndrome (VHL) Who Have VHL Lesions to Follow") at the age of 31. He was treated with $50 \mathrm{mg}$ of sunitinib daily for 28 days, followed by 14 days off. Sunitinib was 
discontinued after two cycles due to adverse events and decrease in blood counts. Subsequently, he underwent a percutaneous cryoablation of the right kidney lesion.

At the age of 39 years, he reported intense midline lower back pain at the time associated with a $3.1 \mathrm{~cm}$ $\mathrm{HB}$ at the left T10 nerve root (Fig. 1A and E). He reported that the pain was especially severe upon movement and taking as needed non-steroidal anti-inflammatory agents. He was started on off-label oral propranolol (220mg daily, dose was calculated as $3 \mathrm{mg} / \mathrm{kg} /$ day over three doses based on the indication for $(\mathrm{H})$, which partially improved his pain and required less pain medication. However, the lesion continued to grow from $3.1 \mathrm{~cm}$ to $3.7 \mathrm{~cm}$ over the next two years (Fig. 1B, C, F, G) and a new $8 \mathrm{~mm}$ nonfunctional adrenal mass appeared (Fig. 2A). He was then started on standard dose of $120 \mathrm{mg}$ subcutaneous injections of Lanreotide every 28 days. Within two weeks of the first dose, he noted a decrease in upper back pain and improved sleep quality. He continued to show symptomatic improvement on Lanreotide and is now able to be active and able to taper off his pain medication. Since initiating Lanreotide, the T10 tumor and left adrenal nodule have not shown significant radiographic progression (Fig. 1D and H; Fig. 2B), and no new lesions have been detected. Overall, three years later, he has been largely free of symptoms likely due to pain reduction through growth arrest of the disease burden since the beginning on Lanreotide.

\section{Discussion And Conclusions}

Here we report on a 44-year-old patient with symptom improvement after propranolol and Lanreotide therapy. Currently, there are no approved treatments for patients with VHL related HB. However, reported literature and our case suggest that propranolol and somatostatin receptor agonists may have therapeutic effects in this tumor.

In this case, the patient reported symptom alleviation after beginning on a dose of $220 \mathrm{mg}$ of propranolol per day. A phase III clinical trial evaluated 7 patients who took $120 \mathrm{mg}$ of propranolol per day over 1 year. The study was designed to determine safety and efficacy of propranolol in retinal HB. The number and size of the retinal HB remained stable in all patients [24]. This trial led to the European Medicine Agency's designation of propranolol as an orphan drug for VHL. Shepard et. al, retrospectively reviewed 3 patients who were enrolled on a VHL natural history study and determined that they demonstrated a slower tumor growth rate during propranolol treatment (median growth rate of $13.3 \mathrm{~mm}^{3} /$ year on propranolol and $27.1 \mathrm{~mm}^{3} /$ year without propranolol) [16]. In a report of a 33-year-old female with VHL HBs, propranolol was shown to delay the growth of hemangioblastomas and reduced the intensity and frequency of her migraine headache symptoms [25]. In addition, propranolol has shown an apoptotic effect on HB cell invitro in multiple studies $[16,26,27]$. In this patient, the initial improvement in back pain shortly after beginning on propranolol treatment appeared to be related to initiation of propranolol.

The patient experienced even greater symptom relief after starting on $120 \mathrm{mg}$ Lanreotide injections every 28 days. ${ }^{68} \mathrm{Ga}$-DOTATATE imaging for this patient revealed the presence of somatostatin receptors (SSTRs) and Lanreotide was considered as a potential treatment option. Sizdahkhani et. al, 
demonstrated that the SSTR agonist octreotide led to tumor infarction in a patient with VHL HBs over a period of 6 months. The same study demonstrated in-vitro apoptosis of VHL-HB cells in a dosedependent fashion by the BAX -caspase- 3 pathway [23]. Somatostatin agonist therapy, including Lanreotide, have been successfully used for the treatment of other VHL related tumors [22, 28]; however, prospective randomized studies are needed to determine its efficacy in the use in VHL related HBs. Based on the notable symptom improvement in our patient and the findings of Sizdahkhani et. al, we believe somatostatin agonist therapy may have an antitumor effect in VHL related HBs and that further investigation is warranted.

In conclusion, somatostatin agonist such as Lanreotide and propranolol may have a role in the treatment of VHL-related HB, however, prospective clinical trials are needed to assess the anti-tumor activity of both agents alone and in combination. In addition, further studies are necessary to identify mechanisms of anti-tumor activity of propranolol and somatostatin agonist in VHL-related tumors.

\section{Declarations}

\section{Funding}

The research reported in this publication was supported in part by the Center for Cancer Research, National Institute of Neurological Disorders and Stroke (NINDS), National Cancer Institute (NCl) of the National Institutes of Health $(\mathrm{NIH})$ and the Cancer Moonshot Initiative ${ }^{\mathrm{SM}}$.

\section{Competing Interests:}

The authors declare that they have no competing interests.

\section{Availability of data and materials:}

Data sharing is not applicable to this article as no datasets were generated or analyzed during the current study.

\section{Authors' Contributions:}

MI carried out the literature search and collected the data published. He then worked with the other authors in writing the paper and prepared the original draft.

RA produced the two figures in the manuscript as well as their corresponding figure legends. He also contributed to the preparation and review of the manuscript.

$A C$ is involved with the active management of the patient.

BW worked with the other authors in the preparation and review of the manuscript. 
PC is involved with the active management of the patient. He also worked with the other authors in the preparation and review of the manuscript.

JDR is involved with the active management of the patient. She is the corresponding author as well.

All authors have read and approved the final manuscript.

\section{Ethics approval and consent to participate:}

Not applicable.

\section{Consent for publication:}

Written informed consent for publication of clinical details was obtained from the patient.

\section{References}

1. Latif F, Tory K, Gnarra J, Yao M, Duh FM, Orcutt ML, et al. Identification of the von Hippel-Lindau disease tumor suppressor gene. Science (New York, NY). 1993;260(5112):1317-20. doi: 10.1126/science.8493574.

2. Lonser RR, Glenn GM, Walther M, Chew EY, Libutti SK, Linehan WM, et al. von Hippel-Lindau disease. Lancet (London, England). 2003;361(9374):2059-67. doi: 10.1016/s0140-6736(03)13643-4.

3. Maddock IR, Moran A, Maher ER, Teare MD, Norman A, Payne SJ, et al. A genetic register for von Hippel-Lindau disease. Journal of medical genetics. 1996;33(2):120-7. doi: 10.1136/jmg.33.2.120.

4. Butman JA, Linehan WM, Lonser RR. Neurologic manifestations of von Hippel-Lindau disease. Jama. 2008;300(11):1334-42. doi: 10.1001/jama.300.11.1334.

5. Zbar B, Kishida T, Chen F, Schmidt L, Maher ER, Richards FM, et al. Germline mutations in the Von Hippel-Lindau disease (VHL) gene in families from North America, Europe, and Japan. Human mutation. 1996;8(4):348-57. doi: 10.1002/(sici)1098-1004(1996)8:4<348::Aid-humu8>3.0.Co;2-3.

6. Wilding A, Ingham SL, Lalloo F, Clancy T, Huson SM, Moran A, et al. Life expectancy in hereditary cancer predisposing diseases: an observational study. Journal of medical genetics. 2012;49(4):2649. doi: 10.1136/jmedgenet-2011-100562.

7. Chittiboina P, Lonser RR. Von Hippel-Lindau disease. Handbook of clinical neurology. 2015;132:13956. doi: 10.1016/b978-0-444-62702-5.00010-x.

8. Lonser RR, Butman JA, Huntoon K, Asthagiri AR, Wu T, Bakhtian KD, et al. Prospective natural history study of central nervous system hemangioblastomas in von Hippel-Lindau disease. Journal of neurosurgery. 2014;120(5):1055-62. doi: 10.3171/2014.1.Jns131431.

9. González Escobar AB, Morillo Sánchez MJ, García-Campos JM. [Von Hippel-Lindau disease: family study]. Archivos de la Sociedad Espanola de Oftalmologia. 2012;87(11):368-72. doi: 10.1016/j.oftal.2011.10.005. 
10. Maher ER, Yates JR, Harries R, Benjamin C, Harris R, Moore AT, et al. Clinical features and natural history of von Hippel-Lindau disease. The Quarterly journal of medicine. 1990;77(283):1151-63. doi: 10.1093/qjmed/77.2.1151.

11. Chew EY. Ocular manifestations of von Hippel-Lindau disease: clinical and genetic investigations. Transactions of the American Ophthalmological Society. 2005;103:495-511.

12. Al-Majed AA, Bakheit AHH, Abdel Aziz HA, Alajmi FM, AlRabiah H. Propranolol. Profiles of drug substances, excipients, and related methodology. 2017;42:287-338. doi:

10.1016/bs.podrm.2017.02.006.

13. Léauté-Labrèze $C$, Dumas de la Roque E, Hubiche T, Boralevi F, Thambo JB, Taïeb A. Propranolol for severe hemangiomas of infancy. The New England journal of medicine. 2008;358(24):2649-51. doi: 10.1056/NEJMc0708819.

14. Léauté-Labrèze C, Hoeger P, Mazereeuw-Hautier J, Guibaud L, Baselga E, Posiunas G, et al. A randomized, controlled trial of oral propranolol in infantile hemangioma. The New England journal of medicine. 2015;372(8):735-46. doi: 10.1056/NEJMoa1404710.

15. Albiñana V, Escribano RMJ, Soler I, Padial LR, Recio-Poveda L, Villar Gómez de Las Heras K, et al. Repurposing propranolol as a drug for the treatment of retinal haemangioblastomas in von HippelLindau disease. Orphanet J Rare Dis. 2017;12(1):122-. doi: 10.1186/s13023-017-0664-7.

16. Shepard MJ, Bugarini A, Edwards NA, Lu J, Zhang Q, Wu T, et al. Repurposing propranolol as an antitumor agent in von Hippel-Lindau disease. Journal of neurosurgery. 2018:1-9. doi: 10.3171/2018.5.JNS172879.

17. De Martino MC, Hofland LJ, Lamberts SW. Somatostatin and somatostatin receptors: from basic concepts to clinical applications. Progress in brain research. 2010;182:255-80. doi: 10.1016/s00796123(10)82011-4.

18. Sharma P, Dhull VS, Bal C, Malhotra A, Kumar R. Von Hippel-Lindau syndrome: demonstration of entire disease spectrum with (68)Ga-DOTANOC PET-CT. Korean journal of radiology. 2014;15(1):16972. doi: 10.3348/kjr.2014.15.1.169.

19. Oh JR, Kulkarni H, Carreras C, Schalch G, Min JJ, Baum RP. Ga-68 Somatostatin Receptor PET/CT in von Hippel-Lindau Disease. Nuclear medicine and molecular imaging. 2012;46(2):129-33. doi: 10.1007/s13139-012-0133-0.

20. Caplin ME, Pavel M, Ćwikła JB, Phan AT, Raderer M, Sedláčková E, et al. Lanreotide in metastatic enteropancreatic neuroendocrine tumors. The New England journal of medicine. 2014;371(3):224-33. doi: 10.1056/NEJMoa1316158.

21. Cives $M$, Strosberg J. The expanding role of somatostatin analogs in gastroenteropancreatic and lung neuroendocrine tumors. Drugs. 2015;75(8):847-58. doi: 10.1007/s40265-015-0397-7.

22. O'Toole SM, Drake WM. Response to Somatostatin Analog Therapy in a Patient With von HippelLindau Disease and Multiple Pancreatic Neuroendocrine Tumors. Pancreas. 2017;46(7):e57. doi: 10.1097/mpa.0000000000000865. 
23. Sizdahkhani S, Feldman MJ, Piazza MG, Ksendzovsky A, Edwards NA, Ray-Chaudhury A, et al. Somatostatin receptor expression on von Hippel-Lindau-associated hemangioblastomas offers novel therapeutic target. Sci Rep. 2017;7:40822-. doi: 10.1038/srep40822.

24. González-Rodríguez B, Villar Gómez de Las Heras K, Aguirre DT, Rodríguez-Padial L, Albiñana V, Recio-Poveda L, et al. Evaluation of the safety and effectiveness of oral propranolol in patients with von Hippel-Lindau disease and retinal hemangioblastomas: phase III clinical trial. BMJ Open Ophthalmol. 2019;4(1):e000203-e. doi: 10.1136/bmjophth-2018-000203.

25. Perona-Moratalla A, Serrano-Heras G, Segura T. Case Report: Efficacy of propranolol in delaying the growth of hemangioblastomas in a Von Hippel Lindau patient [version 1; peer review: 2 approved with reservations]. 2017;6(256). doi: 10.12688/f1000research.9036.1.

26. Albiñana V, Villar Gómez de Las Heras K, Serrano-Heras G, Segura T, Perona-Moratalla AB, MotaPérez $\mathrm{M}$, et al. Propranolol reduces viability and induces apoptosis in hemangioblastoma cells from von Hippel-Lindau patients. Orphanet J Rare Dis. 2015;10:118. doi: 10.1186/s13023-015-0343-5.

27. Cuesta AM, Albiñana V, Gallardo-Vara E, Recio-Poveda L, de Rojas PI, de Las Heras KVG, et al. The $\beta 2-$ adrenergic receptor antagonist ICI-118,551 blocks the constitutively activated HIF signalling in hemangioblastomas from von Hippel-Lindau disease. Sci Rep. 2019;9(1):10062. doi: 10.1038/s41598-019-46448-6.

28. Yaghobi Joybari A, Azadeh P. Von Hippel-Lindau Disease With Multi-Organ Involvement: A Case Report and 8-Year Clinical Course With Follow-Up. Am J Case Rep. 2017;18:1220-4. doi: $10.12659 /$ ajcr.907356.

\section{Figures}




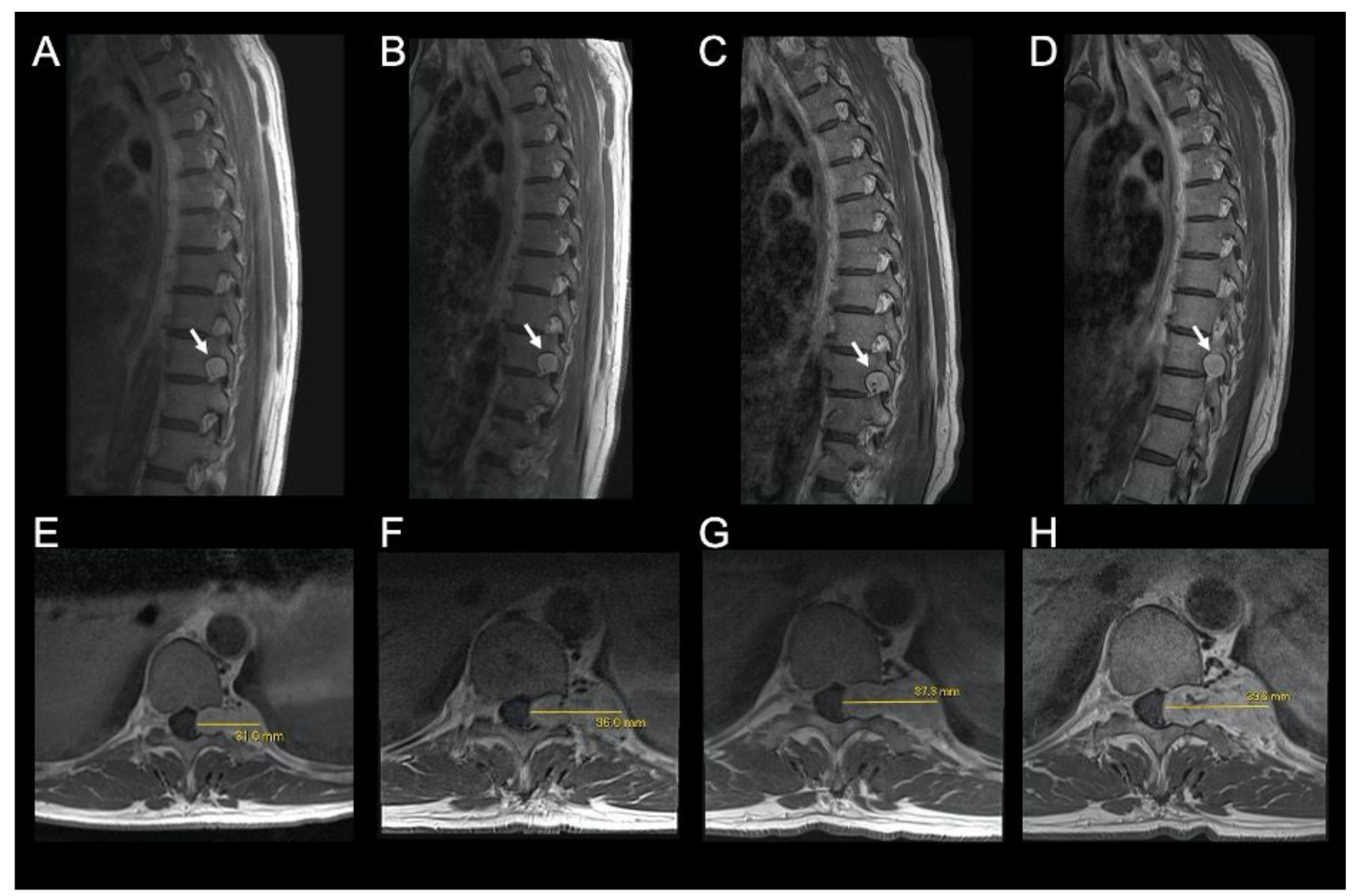

\section{Figure 1}

Thoracic Hemangioblastoma VHL-associated hemangioblastoma of left nerve root at T10 (arrow) shown on sagittal MRI T1 on initial presentation (A), at 1-year follow-up (after 1-year treatment with propranolol) (B), 2-year follow-up (started on Lanreotide) (C), and 1-year after combined treatment with propranolol and Lanreotide (D). Axial T1 images with hemangioblastoma measured across the largest segment are shown $(\mathrm{E}-\mathrm{H})$ corresponding to the time points of the sagittal images above. 


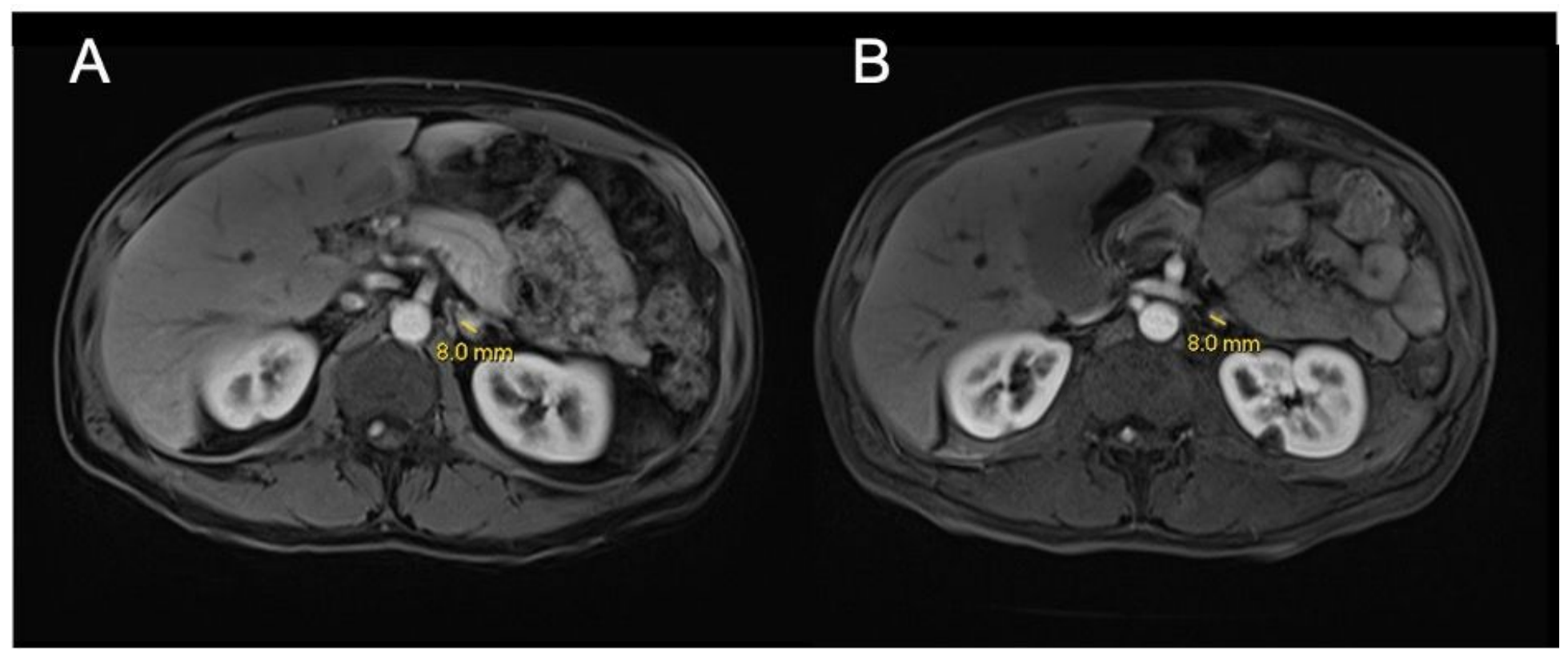

\section{Figure 2}

Adrenal nodule Axial 3D MRI reconstruction showing $0.8 \mathrm{~cm}$ left adrenal nodule (A) which remained stable on follow-up imaging after combined treatment of propranolol and Lanreotide for 1-year (B). 